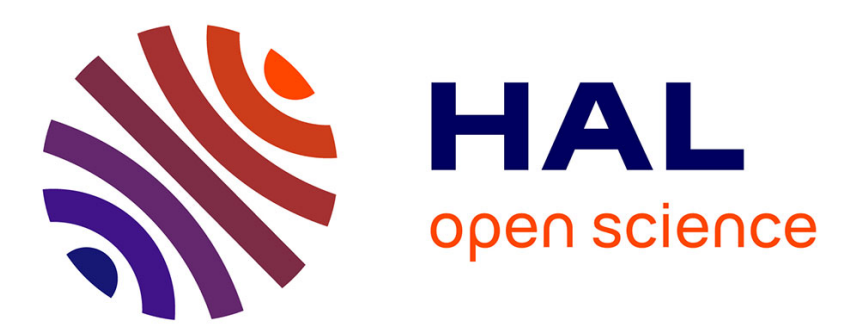

\title{
Predictive value of 6-month decline in ADAS-cog for survival without severe Alzheimer's disease.
}

Catherine Helmer, Sandrine Andrieu, Karine Pérès, Jean-Marc Orgogozo, Bruno Vellas, Jean-François Dartigues

\section{To cite this version:}

Catherine Helmer, Sandrine Andrieu, Karine Pérès, Jean-Marc Orgogozo, Bruno Vellas, et al.. Predictive value of 6-month decline in ADAS-cog for survival without severe Alzheimer's disease.. Dementia and Geriatric Cognitive Disorders, 2007, 23 (3), pp.168-74. 10.1159/000098516 . inserm-00173058

\section{HAL Id: inserm-00173058 https://www.hal.inserm.fr/inserm-00173058}

Submitted on 10 Nov 2009

HAL is a multi-disciplinary open access archive for the deposit and dissemination of scientific research documents, whether they are published or not. The documents may come from teaching and research institutions in France or abroad, or from public or private research centers.
L'archive ouverte pluridisciplinaire HAL, est destinée au dépôt et à la diffusion de documents scientifiques de niveau recherche, publiés ou non, émanant des établissements d'enseignement et de recherche français ou étrangers, des laboratoires publics ou privés. 
Predictive value of 6-month decline in ADAS-cog for survival without severe Alzheimer's disease

Authors: Catherine Helmer ${ }^{1}$, Sandrine Andrieu ${ }^{2,3}$, Karine Pérès ${ }^{1}$, Jean-Marc Orgogozo ${ }^{1,4}$, Bruno Vellas ${ }^{2,3}$, Jean-François Dartigues ${ }^{1}$ for the REAL.fr Group

${ }^{1}$ INSERM U. 593; Université de Bordeaux 2;

146 rue Léo Saignat, 33076 BORDEAUX CEDEX, FRANCE

${ }^{2}$ INSERM U. 558, TOULOUSE, FRANCE

${ }^{3}$ Centre Hospitalier Universitaire, TOULOUSE, FRANCE

${ }^{4}$ Fédération de Neurologie; Centre Hospitalier Universitaire de Bordeaux, Place Amélie Raba Léon, 33076 BORDEAUX CEDEX, FRANCE

Running head title: ADAS-cog and survival without severe AD

\section{Corresponding author:}

Catherine Helmer

INSERM U. 593; Université de Bordeaux 2;

146 rue Léo Saignat, 33076 BORDEAUX CEDEX, FRANCE

tel: (33) $557571596 \quad$ fax: (33) 557571486

E-mail: $\underline{\text { Catherine.Helmer@isped.u-bordeaux2.fr }}$ 


\section{ABSTRACT}

Background/Aims: To determine the predictive value of the six-month evolution of the ADAS-cog score in initially mild to moderate AD patients on the risk of death or severe dementia $(\mathrm{MMSE}<10)$ within two years.

Methods: Cognition was assessed every six months using the ADAS-cog scale in the Real.fr study, a cohort of AD patients. Six classes of ADAS-cog evolution were distinguished, from the most severe deterioration (decline $\geq 7$ points) to the greatest cognitive improvement (gain $\geq 4$ points).

Results: Among 536 AD patients, 53 (9.9\%) had a six-month decline of seven points or more. This group with the most severe deterioration was significantly associated with the risk of severe dementia or death at two years $(\mathrm{RR}=3.8,95 \% \mathrm{CI} 2.1-6.8)$, even after adjustment for baseline MMSE, disability and ADAS-cog score (RR=2.6, 95\%CI 1.4-5.0). In addition, subjects with a decline by at least four points were also at greater risk of severe dementia.

Conclusion: These results confirm the value of the ADAS-cog scale as a judgement criterion in clinical trials since it is a good surrogate marker of long-term prognosis. The proportion of fast decliners on the ADAS-cog could be a helpful judgement criterion for future trials in AD. 


\section{INTRODUCTION}

Most clinical trials carried out to evaluate the efficacy of drugs in Alzheimer's Disease (AD) have been based on a short-term follow-up (usually six months). Moreover, the judgement criteria used has been the evolution of cognition of the patients (most often the Alzheimer's Disease Assessment Scale-cognitive subscale (ADAS-cog)[1] as both recommended by the US Food and Drug Administration (FDA)[2] and the European Medicine Assessment Agency (EMEA).[3] The score of this scale ranges from 0 (no impairment) to 70 (very severe impairment). To evaluate the efficacy of drugs in these trials, statistical analyses compared the mean decline in ADAS-cog during six months in each treatment group or plus, for the EMEA, the proportions of patients classified as "responders" to the drug (if gain in ADAS-cog score was greater or equal to four points) during the same period of follow-up.[4] However, despite a regular greater gain of 2 to 3 points of ADAS-cog in the treatment group compared to placebo in the trials, [5] or a regular greater proportion of responders in the treatment group, the efficacy of Cholinesterase Inhibitors (ChEIs) remains controversial in mild to moderate AD.[6,7] One of the main subjects of controversy is the lack of clinically meaningful information from such a small ADAS-cog gain (or decline) on a 70 point-scale for physicians, patients and caregivers.[8,9] Although statistically significant, the clinical meaning of outcome measures in AD trials needs to be demonstrated.[10] In the Facing Dementia Survey, only $41 \%$ of physicians, $30 \%$ of caregivers and $24 \%$ of the subjects from the general population considered the efficacy of these medications as credible.[11]

The identification of what represents a decline or a gain of some points on the ADAS$\operatorname{cog}$ after six months in term of long-term prognosis would be one way to increase the credibility of ChEIs. Such an analysis could demonstrate whether the short-term change of the ADAS-cog score constitute a good surrogate marker for the long-term outcome of the patients. The severe stage of the disease represents the time spent with major disability in 
activities of daily living for the patient, frequently with behavioural impairments, which both represent an important burden for the caregivers and make the greatest part of the cost of AD for society and family.[12] The transition to this stage occurs when fulltime caregiving assistance is required in all aspects of daily life, so that life without that support would not be possible.[13] Delaying this devastating stage of AD would be most valuable for the patients, their families and finally the community, including in economical terms. In addition to this severe stage, survival of the patients is essential to consider, since it is probably also a good indicator of the efficacy of a drug treatment. Moreover, it is a censoring event for the risk of severe dementia, and in some cases, it can be an indicator of rapid deterioration which occurred before the follow-up visit. Thus, the risk of severe dementia or death (and the opposite survival without dementia) certainly represents one of the most meaningful indicators of the long-term efficacy of the patient's management. This indicator would provide physicians with realistic information concerning treatment options and expectations to be communicated to $\mathrm{AD}$ patients and their families.

The Real.fr study, a French cohort of AD patients, provides us with the opportunity to evaluate the evolution of the ADAS-cog score, with regular evaluations and to analyse the long-term outcome of the subjects in term of survival without severe dementia. The aim of this paper is to determine the predictive value of the six-month evolution of the ADAS-cog score in initially mild to moderate AD patients on the risk of death or severe dementia within two years.

\section{MATERIALS AND METHODS}

The Real.fr ("Réseau sur la maladie d'Alzheimer Français") is a prospective French multicenter cohort designed to study the natural history of AD and its modalities of 
management. The study population included 686 elderly community-dwelling AD patients followed-up every six months. These patients were consecutively recruited after a consultation in one of 16 Memory clinics. The study method has been presented in full in a previous paper.[14] In brief, all patients met the DSM IV and NINCDS-ADRDA criteria for $\mathrm{AD},[15,16]$ lived in the community at the time of enrolment and were looked after by an informal caregiver. Patients with severe dementia (Mini-Mental State Examination[17] (MMSE) score<10), who were unable to travel or those with a concomitant disorder which affected the diagnosis in the short term were excluded from the study. The Real.fr study has been approved by an ethical review committee and patients and caregivers have signed an informed consent for participation.

At baseline screening, each patient underwent structured comprehensive investigations including the MMSE and the ADAS-cog scale.[1] Disability for basic activities of daily living, including ability for bathing, dressing, toileting, transferring and eating was also assessed. Patients were followed-up every six months with the same cognitive battery. If patients did not have a follow-up visit, major events which had occurred over the previous six months were collected, in particular hospitalisation, institutionalisation, or death.

Statistical Analysis System software version 8.2 was used for analyses. Since survival without severe dementia is a pragmatic approach, we performed analyses together for the risk of severe dementia or death. However, we also presented results separately for these two conditions. In the present article, subjects were considered as having severe (or very severe) dementia at a given follow-up screening if their MMSE score was lower than 10, as recommended by the French Consensus Statement on Dementia of Alzheimer type in the severe stage.[12] Subjects included in the analyses were those with no severe dementia after six months of follow-up and who performed the ADAS-cog scale at baseline and at the sixmonth-follow-up. From the distribution of the six-month evolution of the ADAS-cog score, 
six ordinal classes of evolution were distinguished according to the deciles of the distribution for the extreme groups and the quintiles for the others. An increase in the ADAS-cog score reflects a cognitive deterioration and was named "decline". On the other hand, the term "gain" was used to characterise an improvement in cognitive performances, i.e. a decrease of the score. The six classes were as followed: Group I: decline of seven points or more (most severe deterioration); Group II: decline of 4 to 6 points; Group III: decline of 2 to 3 points; Group IV: decline of one point to gain of one point; Group V: gain of 2 or 3 points; Group VI: gain of 4 points and more (greatest cognitive improvement). The risk of severe dementia or death, according to the class of evolution of the ADAS-cog was estimated over a two-year period. Cox proportional hazards model with delayed entry, in which the time-scale was the individuals' age, was performed to estimate these relative risks of severe dementia or death and the ninety-five per cent Confidence Interval (95\% CI) for each class of evolution of the ADAS-cog.[18] Group IV was defined as the reference group, since it was considered as stable (decline of one point to gain of one point). The analyses were controlled for sex, baseline MMSE score, ADAS-cog score and ADL-disability; patients who needed help for at least one activity were classified as ADL-disabled. All these analyses were also performed separately for severe dementia and death. Finally a sensitivity analysis of the results was conducted taking into account the patients who were lost to follow-up or refused to participate after the 6-month examination. Firstly, we made the assumption that all the non-followed-up patients developed severe dementia or died; secondly, that all of them survived and were free of severe dementia. Logistic regression models adjusted for sex were used to perform this sensitivity analysis, providing estimation of Odds Ratio (OR) and 95\% Confidence Interval. 


\section{RESULTS}

Of the 686 AD patients, $536(78.1 \%)$ were eligible for this analysis. The 150 excluded patients were the non-followed-up at 6 months $(n=117)$, those with a MMSE lower than 10 at 6-months $(n=20)$ or those who did not performed the ADAS-cog scale at baseline or at the 6month follow-up $(n=13)$. The eligible patients were on average 77.6 years old (SD: 6.8) and $388(72.4 \%)$ were women (Table 1). About $88 \%$ were treated with ChEIs at baseline. Among these patients, the six-month decline of the ADAS-cog score was of seven points or more (Group I, most severe deterioration) in 53 patients (9.9\%), between 4 and 6 points (Group II) in 72 patients $(13.4 \%)$ and 2 or 3 points (Group III) in 100 patients (18.7\%). The reference group (Group IV) characterized by a decline of one point, a stability of the ADAS-cog score or a gain of one point was constituted of 211 patients (39.4\%). Fifty-four patients $(10.1 \%)$ had a gain of 2 to 3 points (Group V) and 46 patients (8.6\%) a gain of more than 4 points (Group VI). Over the two-year period, 52 patients were lost to follow-up or refused to participate after the 6-month examination. No differences of follow-up were observed either by the group of cognitive decline (Chi square test $=1.36, \mathrm{p}=0.93$ ) or by other characteristics at baseline (Table $1)$.

The risk of severe dementia or death was estimated on 484 patients, those who had at least one follow-up visit after the 6-month examination or died over the follow-up period. Thirty-nine patients $(8.1 \%)$ died and $63(13 \%)$ developed a severe dementia within the two years of follow-up. Compared to the reference group (Group IV), the frequency of death or severe dementia was significantly higher $\left(\chi^{2}=27.8, \mathrm{p}<0.0001\right)$ in Group I, with $52.2 \%$ of death or severe dementia at two years (Table 2). These frequencies were almost similar for the three groups characterized by a small cognitive evolution (decline or gain of ADAS-cog score), with $15.8 \%, 14.3 \%$ and $14.0 \%$ for groups IV, V and VI respectively. The proportions of death 
or severe dementia appeared to be intermediate for groups II (21.5\%) and III (23.1\%), but not significantly different compared to the reference group.

When regarding severe dementia separately, although frequency of severe dementia appeared to be highest in Group I (41.5\%, p<0.0001 compared to Group IV), these frequencies were also significantly higher in Group II $(15.9 \%, \mathrm{p}=0.035)$ and III $(14.8, \mathrm{p}=0.04)$ compared to Group IV. For death separately, none of the groups significantly differed compared to the reference group.

The Relative Risks (RR) of severe dementia or death controlled for sex are given in Table 3. The global effect of the evolution of ADAS-cog score was significant for the risk of death and severe dementia $(\mathrm{p}<0.001)$. Among the six groups of evolution of ADAS-cog score, Group I was the only significant predictor and was associated with the risk of severe dementia or death $(\mathrm{RR}=3.8, \mathrm{p}<0.0001)$. After adjustment on the MMSE score at baseline, this risk decreased but remained significant $(R R=2.3,95 \%$ CI: 1.2 - 4.3, $p=0.0102)$. Results were unchanged after controlling also for baseline ADL-disability and baseline ADAS-Cog score (Table 3).

The sensitivity analysis did not modify the results. Group I was once again the only significant predictor of the risk of severe dementia or death, but the odds ratios were higher with greater confidence intervals. The odds ratio was estimated at 4.4 (95\% CI: 2.3-8.2, $\mathrm{p}<0.0001)$ when the entire non followed-up patients were considered as being at a severe stage of dementia or dead and at $4.9(95 \%$ CI: 2.5-9.6, p<0.0001) when they were all considered alive and free of severe dementia.

When regarding separately severe dementia, the three groups which demonstrated decline in the ADAS-cog score were significant predictors of severe dementia when controlled for sex only (Table 3). After adjustment for baseline MMSE score, ADL-disability and ADAS-cog score, only the groups of greater decline on the ADAS-cog (Groups I and II) 
remained significant predictors of severe dementia. When analysing the risk of death, however, none of the groups of ADAS-cog evolution was predictor of death at two years.

\section{DISCUSSION}

We showed that mild to moderate AD patients who declined by at least seven points on the ADAS-cog scale during an initial period of six months were at higher risk of severe dementia or death after two years of evolution. In this group of patients, $52.2 \%$ died or worsened to reach the severe stage of dementia in two years versus less than $25 \%$ in the other groups of evolution of the ADAS-cog. In addition, subjects who declined by at least four points on the ADAS-cog scale were also at greater risk of severe dementia, while evolution of the ADAS-cog scale did not specifically predict death at two years. Alone, these findings are not really surprising since an association between cognitive decline and survival has been already shown in AD patients.[19, 20] However, in previous studies, cognitive decline was measured over the whole course of the disease or over a long period (two years) and not during a short period of 6 months. Thus, these papers focused more on a correlation between cognitive decline and poor outcome than a real prediction for survival without severe dementia, as in the present article.

Two results of our study are particularly of interest and, to our knowledge, original. Firstly, the predictive value of the six-month decline seems to be limited to a group of fast decliners and was not significant for the other groups of patients, from moderate decliners to no decliners. This finding means that within the known heterogeneity of the course of AD a group of patients, who were fast decliners from a cognitive point of view, could be identified as having a particularly bad prognosis. The limit to define fast decliners, at least seven points of decline or at least four points of decline on the ADAS-cog score, differed when analysing 
severe dementia and death together or separately. However, combining these two outcomes is a more pragmatic approach and thus, appears to be more appropriate in the follow-up of patients.

Secondly, these results were obtained with the ADAS-cog scale, which is one of the most often used cognitive judgement criteria of efficacy in anti-dementia drugs trials. They confirm the value of the ADAS-cog scale as judgement criterion in short term clinical trials since it is a good surrogate marker of the long term risk of survival without severe dementia. These results therefore suggest that the proportion of fast decliners ( 7 points or more of the ADAS-cog) after six months of treatment could be a judgement criterion for future trials.

In our results, although evolution of the ADAS-cog score was significantly associated with survival without dementia, it was not a significant predictor of death alone. This result is probably explained by the causes of death in AD patients, where death is often due to another pathology than $\mathrm{AD}$, and thus not specific and not associated with its evolution.

Our study has limits that should be discussed. Firstly, the definition of severe dementia is only based on the MMSE score, conventionally set at 10.[21] However, this definition is the lower limit of indication of cholinesterase inhibitors in AD patients and is widely accepted as the cut-off for this phase of the disease.[13] Secondly, 52 patients were lost to follow-up or refused the follow-up screenings $(9.7 \%)$, but the proportion of these patients was almost the same in each group of cognitive evolution. Moreover, with sensitivity analyses considering both hypotheses, that all these patients became severely impaired or died, and conversely that all were still alive and free of severe dementia after two years, the main result remained unchanged. Thirdly, we defined six groups according to the magnitude of the decline and only one appeared to be a predictor of death or severe dementia. Even after application of the Bonferroni rule (for multiplicity of statistical tests), which is very conservative, the p value remained lower than 0.008 , still very significant. Fourthly, patients in the group of fast 
decliners tended to be younger $(\mathrm{p}=0.058)$ and had a lower MMSE score at baseline $(\mathrm{p}<0.001)$. However, the poor prognosis of this group remained unchanged after controlling for these characteristics.

Long-term progression is a very important outcome in chronic disease. Since clinical trials can not be performed over a very long period, for reasons of convenience and because of a high drop-out rate, surrogate markers - or predictors - of long-term evolution can be very useful. The proportion of fast decliners of the ADAS-cog over a six-month period could be proposed as a judgement criterion for future trials in $\mathrm{AD}$ and also allows to assess selectively the later efficacy and efficiency of drug treatments in this subgroup of patients most at risk of poor outcome. 


\section{ACKNOWLEDGMENTS}

This work was supported by grants from the French Ministry of Health (PHRC 1998/2001 $\left.\mathrm{n}^{\circ} 18-05 / 0101001\right)$.

The REAL.FR Group: Principal investigator: Pr B. Vellas (Toulouse); Associate investigators: Pr M. Rainfray, Dr S. Richard-Harston (Bordeaux); Pr A. Franco, Dr P. Couturier (Grenoble); Pr F. Pasquier, Dr M. Mackowiak, V. Sorel (Lille); Dr B. Frigard, Dr H. Idiri, Dr K. Gallouj (Lille); Dr B. Michel, L. Margulies (Marseille); Pr Cl. Jeandel (Montpellier); Pr J. Touchon, Dr F. Portet, Dr S. Lerouge (Montpellier); Pr Ph. Robert, Dr P. Brocker, C. Bertogliati (Nice); Pr B. Forette, Dr L. Teillet, Dr L. Lechowski (Paris); Pr J. Belmin, Dr S. Pariel-Madjelssi (Paris); Pr M. Verny, Dr MA. Artaz (Paris); Pr F. Forette, Dr AS. Rigaud, Dr F. Latour (Paris); Pr P. Jouanny, Dr S. Belliard, Dr O. Michel (Rennes); Dr C.

Girtanner, Dr Thomas-Anterion (Saint Etienne); Study coordinators: F. Cortes, Dr S.

Gillette-Guyonnet, Pr F. Nourhashemi, Dr P.J. Ousset (Toulouse); Epidemiologist: Dr S. Andrieu; Data processing: C. Cantet (Toulouse) 


\section{REFERENCES}

1. Rosen WG, Mohs RC, Davis KL: A new rating scale for Alzheimer's disease. Am J Psychiatry 1984;141:1356-1364.

2. Food Drugs and Cosmetic Reports. FDA guidance on Alhzeimer's drug clinical utility assessments. In. Washington DC: FDA Report, 1992: 13-15.

3. The European Agency for the Evaluation of Medicinal Products (EMEA). Human Medicines Evaluation Unit. Committee for Proprietary Medicinal Products (CPMP). Note for guidance on medicinal products in the treatment of Alzheimer's disease. In. London, 1997: http://www.emea.eu.int/pdfs/human/ewp/055395en.pdf.

4. Rosler M, Anand R, Cicin-Sain A, Gauthier S, Agid Y, Dal-Bianco P, Stahelin HB, Hartman R, Gharabawi M: Efficacy and safety of rivastigmine in patients with Alzheimer's disease: international randomised controlled trial. Bmj 1999;318:633-638.

5. Birks J: Cholinesterase inhibitors for Alzheimer's disease. Cochrane Database Syst Rev 2006:CD005593.

6. Kaduszkiewicz H, Zimmermann T, Beck-Bornholdt HP, van den Bussche H: Cholinesterase inhibitors for patients with Alzheimer's disease: systematic review of randomised clinical trials. Bmj 2005;331:321-327.

7. Lanctôt KL, Herrmann N, Yau KK, Khan LR, Liu BA, Loulou MM, Einarson TR: Efficacy and safety of cholinesterase inhibitors in Alzheimer's disease: a meta-analysis. Can Med Assn J 2003;169:557-564.

8. Schneider LS: The post-modern world of Alzheimer's disease trials: how much is an ADAS-cog point worth in central London? Int J Geriatr Psychiatry 2006;21:9-13.

9. Takeda A, Loveman E, Clegg A, Kirby J, Picot J, Payne E, Green C: A systematic review of the clinical effectiveness of donepezil, rivastigmine and galantamine on cognition, 
quality of life and adverse events in Alzheimer's disease. Int J Geriatr Psychiatry 2006;21:1728.

10. Hogan DB: Donepezil for severe Alzheimer's disease. Lancet 2006;367:1031-1032.

11. Rimmer E, Wojciechowska M, Stave C, Sganga A, O' Connell B: Implications of the Facing Dementia Survey for the general population, patients and caregivers across Europe. International Journal of Clinical Practice 2005;59 Suppl. 146:17-24.

12. Vellas B, Gauthier S, Allain H, Andrieu S, Aquino JP, Berrut G, Berthel M, Blanchard F, Camus V, Dartigues JF, Dubois B, Forette F, Franco A, Gonthier R, Grand A, Hervy MP, Jeandel C, Joel ME, Jouanny P, Lebert F, Michot P, Montastruc JL, Nourhashemi F, Ousset PJ, Pariente J, Rigaud AS, Robert P, Ruault G, Strubel D, Touchon J, Verny M, Vetel JM: Consensus statement on dementia of Alzheimer type in the severe stage. J Nutr Health Aging 2005;9:330-338.

13. Feldman HH, Woodward M: The staging and assessment of moderate to severe Alzheimer disease. Neurology 2005;65 (Supp13):S10-S17.

14. Gillette-Guyonnet S, Nourhashemi F, Andrieu S, Cantet C, Micas M, Ousset PJ, Vellas B: The REAL.FR research program on Alzheimer's disease and its management: methods and preliminary results. J Nutr Health Aging 2003;7:91-96.

15. American Psychiatry Association. Diagnosis and Statistical Manual of Mental Disorders, 4th ed (DSM-IV). In: APA, ed. Washington DC, 1994.

16. Mc Khann G, Drachman D, Folstein M, Katzman R, Price D, Stadlan E: Clinical diagnosis of Alzheimer's disease: report of the NINCDS-ADRDA work group under the auspices of Department of Health and Human services Task Force on Alzheimer's disease. Neurology 1984;34:939-944.

17. Folstein MF, Folstein SE, McHugh PR: Mini Mental State: a practical method for grading the cognitive state of patients for the clinician. J Psychiatr Res 1975;12:189-192. 
18. Commenges D, Letenneur L, Joly P, Alioum A, Dartigues JF: Modelling age-specific risk: application to dementia. Stat Med 1998;17:1973-1988.

19. Hui JS, Wilson RS, Bennett DA, Bienias JL, Gilley DW, Evans DA: Rate of cognitive decline and mortality in Alzheimer's disease. Neurology 2003;61:1356-1361.

20. Nguyen HT, Black SA, Ray LA, Espino DV, Markides KS: Cognitive impairment and mortality in older mexican americans. J Am Geriatr Soc 2003;51:178-183.

21. National Institute for Clinical Excellence (NICE). Appraisal Consultation Document: Alzheimer's disease - donepezil, rivastigmine, galantamine and memantine (review). In, 2006: http://www.nice.org.uk/page.aspx?o=245908. 
Table 1: Follow-up status of patients according to baseline characteristics and evolution of the ADAS-cog score at 6 months

\begin{tabular}{|c|c|c|c|}
\hline Characteristics & Followed-up & Non followed-up & Total \\
\hline Age at baseline: mean (SD; range) & $77.6(6.9 ; 51-95)$ & $77.0(6.2 ; 64-95)$ & $77.6(6.8 ; 51-95)$ \\
\hline Women: n $(\%)$ & $347(71.2)$ & $41(78.9)$ & $388(72.4)$ \\
\hline Treatment with ChEIs at baseline: $\mathrm{n}(\%)$ & $426(88.0)$ & $44(84.6)$ & $470(87.7)$ \\
\hline MMSE at baseline: mean (SD) & $20.5(4.0)$ & $19.7(4.5)$ & $20.4(4.1)$ \\
\hline ADAS-cog at baseline: mean (SD) & $17.0(7.2)$ & $17.3(7.8)$ & $17.0(7.2)$ \\
\hline ADL-disability: n (\%) & $172(35.5)$ & $22(42.3)$ & $194(36.2)$ \\
\hline \multicolumn{4}{|l|}{ Evolution of ADAS-cog score at 6 months } \\
\hline - group I (decline $>=7$ points): $\mathrm{n}(\%)$ & $46(9.5)$ & $7(13.5)$ & $53(9.9)$ \\
\hline - group II (decline 4-6 points): n (\%) & $65(13.4)$ & $7(13.5)$ & $72(13.4)$ \\
\hline - group III (decline 2-3 points): n (\%) & $91(18.8)$ & $9(17.3)$ & $100(18.7)$ \\
\hline - group IV (stable, reference group): n (\%) & $190(39.3)$ & $21(40.4)$ & $211(39.4)$ \\
\hline - group V (gain 2-3 points): n (\%) & $49(10.1)$ & $5(9.6)$ & $54(10.1)$ \\
\hline - group VI (gain >= 4 points): $\mathrm{n}(\%)$ & $43(8.9)$ & $3(5.8)$ & $46(8.6)$ \\
\hline Total & 484 & 52 & 536 \\
\hline
\end{tabular}


Table 2: Proportion of combined death or severe dementia and severe dementia and death alone, according to the group of evolution of the ADAS-cog score

Death or severe Severe dementia
dementia

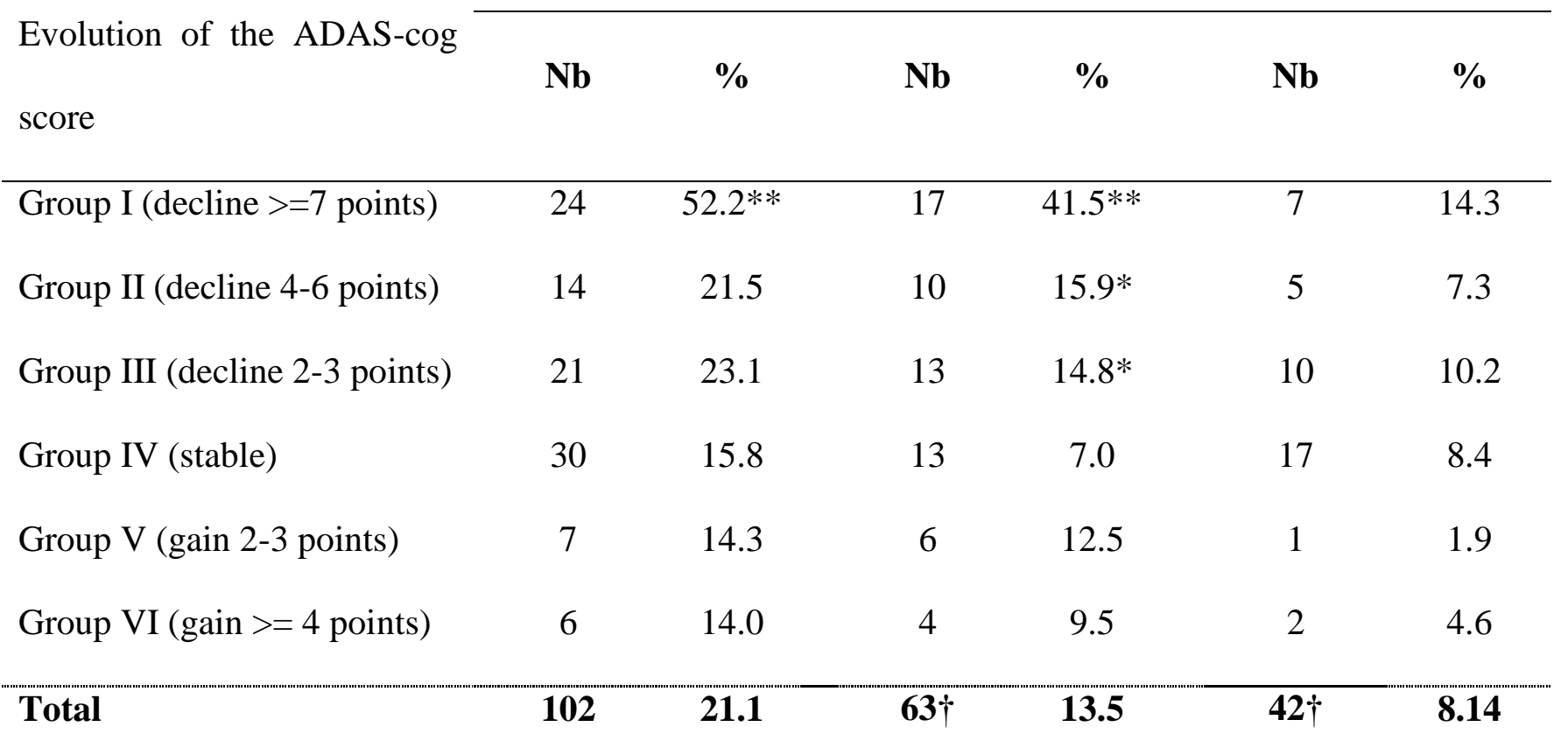

$* * \mathrm{p}<0.001, * \mathrm{p}<0.05 ; \mathrm{p}$-value for the Chi square test comparing each group to the reference category, the Group IV

$\uparrow 3$ subjects have experienced severe dementia before dying 
Table 3: Relative risks of death or severe dementia combined and severe dementia and death alone, according to the group of evolution of the ADAS-cog score

\begin{tabular}{|c|c|c|c|c|}
\hline \multirow{2}{*}{ Evolution of the ADAS-cog score } & \multicolumn{2}{|c|}{ Model 1 ${ }^{\mathrm{a}}$} & \multicolumn{2}{|c|}{ Model $2^{b}$} \\
\hline & $\mathbf{R R}$ & $95 \% \mathrm{CI}$ & $\mathbf{R R}$ & $95 \% \mathrm{CI}$ \\
\hline \multicolumn{5}{|l|}{ Severe dementia or death } \\
\hline Group IV (stable, reference group) & 1 & - & 1 & - \\
\hline Group I (decline >=7 points) & $3.8^{* *}$ & $2.1-6.8$ & $2.6^{* *}$ & $1.4-5.0$ \\
\hline Group II (decline 4-6 points) & 1.5 & $0.76-3.0$ & 1.6 & $0.8-3.2$ \\
\hline Group III (decline 2-3 points) & 1.6 & $0.89-2.8$ & 1.5 & $0.8-2.7$ \\
\hline Group V (gain 2-3 points) & 1.1 & $0.46-2.6$ & 0.6 & $0.3-1.5$ \\
\hline Group VI (gain >= 4 points) & 0.9 & $0.35-2.1$ & 0.5 & $0.2-1.3$ \\
\hline \multicolumn{5}{|l|}{ Severe dementia } \\
\hline Group IV (stable, reference group) & 1 & - & 1 & - \\
\hline Group I (decline >=7 points) & $5.7 * *$ & $2.6-12.5$ & $3.9 * *$ & $1.6-9.8$ \\
\hline Group II (decline 4-6 points) & $2.6^{*}$ & $1.1-6.2$ & $3.0 *$ & $1.2-7.5$ \\
\hline Group III (decline 2-3 points) & $2.3^{*}$ & $1.01-5.1$ & 2.1 & $0.9-5.2$ \\
\hline Group V (gain 2-3 points) & 1.8 & $0.6-5.0$ & 0.9 & $0.3-2.6$ \\
\hline Group VI (gain >= 4 points) & 1.3 & $0.4-4.0$ & 0.8 & $0.2-2.5$ \\
\hline \multicolumn{5}{|l|}{ Death } \\
\hline Group IV (stable, reference group) & 1 & - & 1 & - \\
\hline Group I (decline $>=7$ points) & 1.7 & $0.7-4.3$ & 1.4 & $0.5-3.8$ \\
\hline Group II (decline 4-6 points) & 0.7 & $0.2-2.0$ & 0.7 & $0.2-1.9$ \\
\hline Group III (decline 2-3 points) & 1.3 & $0.6-2.9$ & 1.2 & $0.5-2.8$ \\
\hline Group V (gain 2-3 points) & 0.3 & $0.04-2.5$ & 0.3 & $0.04-2.5$ \\
\hline Group VI (gain >= 4 points) & 0.4 & $0.1-1.8$ & 0.3 & $0.1-1.6$ \\
\hline
\end{tabular}

${ }^{\mathrm{a}}$ Adjusted for sex

b Adjusted for sex, baseline MMSE score, baseline ADAS-cog score and baseline ADLdisability

$* * \mathrm{p}<0.01, * \mathrm{p}<0.05$ 